\title{
Mini-placa como ancoragem ortodôntica: relato de caso
}

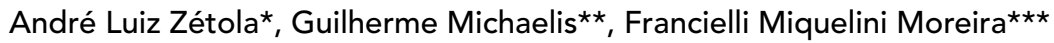

\section{Resumo}

Seria dispensável afirmar que o controle da ancoragem é fundamental para o sucesso do tratamento ortodôntico, sem ela seria impossível a obtenção de uma oclusão ideal através de uma mecânica ortodôntica. O advento da utilização de dispositivos rígidos, originários dos princípios da traumatologia de face e da implantodontia, para a ancoragem rígida na Ortodontia, principalmente nos casos da dificuldade ou impossibilidade da sua obtenção, revolucionou a forma de tratar casos que tinham um prognóstico insatisfatório. O objetivo desse artigo foi revisar a literatura em relação ao uso dos pinos de ancoragem ortodôntica, relatar um caso com a sua utilização e discutir alguns aspectos em relação à ancoragem rígida na Ortodontia. A ancoragem rígida foi utilizada em uma paciente do gênero feminino, com 39 anos de idade que possuía os elementos 26 e 27 com extrusão importante devido à ausência dos antagonistas. Foi instalado um aparelho fixo superior, utilizando uma barra transpalatina nos elementos dentários 15 e 25 para ancoragem com objetivo de intruir os molares superiores esquerdos e o dispositivo quadri-hélice para auxiliar no descruzamento do dente 18. Como a intrusão ortodôntica com apenas ancoragem dentária não havia tido um resultado muito satisfatório até então, foi instalada uma placa de titânio em forma de "L" na região apical dos elementos 26 e 27 com o objetivo de obter uma ancoragem ortodôntica rígida para a intrusão desses elementos. $\mathrm{O}$ tempo de força intrusiva através de elásticos verticais foi de cinco meses e a intrusão obtida foi de $6 \mathrm{~mm}$. Após a remoção do aparelho ortodôntico, fez-se a clareação dentária superior e inferior, instalação de prótese definitiva sobre os implantes e reabilitação estética dentária. Através dos relatos anteriores e da presente experiência, além de outros casos ainda não concluídos, pode-se sugerir que a utilização da ancoragem rígida pode ser utilizada com bastante propriedade no tratamento ortodôntico qunado for requerida uma ancoragem máxima.

Palavras-chave: Ancoragem ortodôntica. Intrusão. Mini-placas de titânio.

\footnotetext{
* Especialista em CTBMF pela UERJ. Mestre em cirurgia de cabeça e pescoço (Complexo Hospitalar Heliópolis). Doutor em implantodontia pela UFSC.

** Especialista em Ortodontia e Ortopedia Facial /Unopar-Londrina.

*** Aluna da graduação da Universidade Tuiuti do Paraná- UTP.
} 


\section{INTRODUÇÃO}

Seria dispensável afirmar que o controle da ancoragem é fundamental para o sucesso do tratamento ortodôntico, sem ela seria impossível a obtenção de uma oclusão ideal através de uma mecânica ortodôntica ${ }^{3}$. A ancoragem dentária é uma das grandes limitações do tratamento da Ortodontia moderna, porque os dentes só podem ser movimentados ortodonticamente através da resposta de forças, portanto sem um apoio não haverá o movimento oposto ${ }^{1}$. Quando se observa uma ausência dentária, principalmente na região posterior, que não é reabilitada proteticamente logo após a exodontia, os dentes adjacentes tendem a inclinar e girar, os antagonistas a extruir, logo a mecânica ortodôntica torna-se bastante trabalhosa nesses casos, principalmente quando se necessita do movimento de intrusão dos molares ${ }^{7}$.

A obtenção e o controle de uma adequada ancoragem são cruciais para o sucesso da Ortodontia e da Ortopedia Facial, tanto é que, nos casos aonde existem limitações desses, muitas vezes, os pacientes são submetidos a tratamentos alternativos com métodos e resultados menos desejáveis para compensar a dificuldade de ancoragem (remoção de dentes permanentes, cirurgia ortognática e aparelhos extrabucais) $)^{8}$. Para solucionar os casos complexos, como a intrusão de dentes posteriores, a mordida aberta anterior e o fechamento de espaço aonde a ancoragem é crítica, Park et al. ${ }^{7}$ sugeriram usar as mini-placas na Ortodontia com a finalidade de obter uma ancoragem ortodôntica absoluta.

O advento da utilização de dispositivos rígidos, originários dos princípios da traumatologia de face e da implantodontia, para a ancoragem rígida na Ortodontia, principalmente nos casos da dificuldade ou impossibilidade da sua obtenção, revolucionou a forma de tratar casos que tinham um prognóstico insatisfatório. Apesar do custo financeiro e biológico, isto é, uma intervenção cirúrgica para colocação e outra para a remoção dos dispositivos, os benefícios dessa modalidade de tratamento tem obtido bons resultados.

O objetivo desse artigo foi revisar a literatura em relação ao uso dos pinos de ancoragem ortodôntica, relatar um caso com a sua utilização e discutir alguns aspectos em relação à ancoragem rígida na Ortodontia.

\section{REVISÃO DE LITERATURA}

A ancoragem dentária pode ser usada como auxílio no tratamento ortodôntico, entretanto para movimentos dentários aonde a ancoragem tem que ser máxima, o uso do dispositivo extrabucal seria o mais indicado. Esses dispositivos são muito utilizados e possuem uma boa eficiência, porém são dependentes da cooperação do paciente, podendo afetar a previsibilidade do sucesso e o tempo previsto do tratamento. Implantes dentários ou pinos intra-ósseos poderiam atuar como ancoragem para que movimentos dentários pudessem ser realizados em qualquer direção na ausência de forças recíprocas indesejáveis. Entretanto, para que este procedimento possa ser utilizado clinicamente, mencionaram ser importante compreender os aspectos relacionados à confiabilidade, estabilidade, rejeição, infecção ou qualquer outra patologia associada ${ }^{1}$.

A intrusão dentária é um dos movimentos ortodônticos mais almejados, porém está limitada pela dificuldade de obtenção de uma ancoragem adequada. Segundo Southard et al. ${ }^{9}$, os implantes usados como ancoragem podem ser utilizados potencialmente nestes casos. A proposta do trabalho destes autores, foi comparar a ancoragem ortodôntica usada em dentes e implantes de titânio osseointegrados, com a finalidade de intrusão. O estudo foi realizado em oito cães adultos, dos quais foram extraídos dois dentes inferiores de cada animal (quarto pré-molar), para que houvesse rotação e extrusão dos dentes adjacentes e antagonistas respectivamente. No lado dos implantes a unidade de ancoragem se manteve rígida, na área dos terceiros pré-molares houve rotação horária e intrusão, a qual era desejada. No lado convencional, 
ancoragem dentária, houve rotação anti-horária e não ocorreu intrusão do dente. Os ápices mesial e distal dos terceiros pré-molares, do lado do implante, foram intruídos e distalizados. No lado de ancoragem dentária, os dois ápices (quarto prémolar) sofreram mesialização e extrusão da cúspide mesial e os dois ápices dos terceiros pré-molares se moveram distalmente ${ }^{9}$.

Os implantes dentários convencionais, inseridos sobre o rebordo alveolar, mostram-se limitados no que tange a aplicação de uma força ortodôntica horizontal e, também, desagradáveis aos pacientes devido à severidade da cirurgia, desconforto da cicatrização inicial e dificuldade na higiene bucal. Os mini-implantes para ancoragem ortodôntica, por outro lado, devem ser suficientemente pequenos para serem colocados em qualquer área do osso alveolar, até mesmo no osso apical. Além disso, um procedimento cirúrgico simples habilitaria o cirurgião-dentista ou o próprio ortodontista a realizá-lo, possibilitando-se rápida cicatrização e fácil remoção após a tração ortodôntica ${ }^{4}$. Torna-se de fundamental importância para a correção vertical da mordida aberta esquelética o controle da altura da região dentoalveolar posterior. Contudo, as técnicas biomecânicas tradicionais tais como o posicionamento dos braquetes, a ancoragem extrabucal, a correção vertical com magnetos e a mentoneira vertical com puxada alta, não se mostram efetivas na intrusão dos molares, especialmente em pacientes adultos, em função da extrema dificuldade para se obter uma ancoragem rígida.

Por esta razão, Umemori et al. ${ }^{11}$ desenvolveram um sistema de ancoragem intrabucal esquelética por meio de implantes temporários de mini-placas de titânio na maxila e/ou mandíbula, com o propósito de corrigir mordidas abertas esqueléticas pela intrusão de molares. Concluíram que a intrusão molar associa-se a uma mínima extrusão de incisivos inferiores e uma rotação do plano oclusal no sentido anti-horário. Além disso, o sistema de ancoragem esquelética não apresenta efeitos colaterais indesejáveis, simplifica a mecanoterapia, encurta o tempo de tratamento e minimiza o desconforto do paciente.

É de extrema dificuldade ocorrer a intrusão dos molares com o uso dos procedimentos ortodônticos convencionais, já através da miniplaca como ancoragem rígida pode-se conseguir a intrusão dos mesmos. Além do que, possui inúmeras vantagens: ancoragem rígida e estável, movimento dentário logo após o procedimento, colocação da mini-placa em local necessário, simplifica a mecânica do tratamento, diminui o período do tratamento ortodôntico, minimiza o desconforto durante o tratamento, estética favorável, redução da aparatologia ortodôntica e aumenta a previsibilidade do resultado final ${ }^{10,12}$. Sugawara et al. ${ }^{10}$ também concluíram que, apesar da intrusão dos molares para a correção da mordida aberta ser efetiva, pode ocorrer uma recidiva em aproximadamente trinta por cento dos casos. Dessa forma seria recomendável uma sobrecorreção nesses casos.

Após a colocação das mini-placas, podem ser aplicadas forças que variam entre 100 e 150 gr. para intrusão dos dentes posteriores ${ }^{2}$.

Ohmae et al. ${ }^{6}$ observaram pouca inflamação no tecido ao redor do implante durante o tratamento, nenhuma mobilidade, ausência de infecção peri-implante, leve reabsorção na região de furca e ápice dos dentes movimentados, e finalmente, houve a formação de cemento no local aonde foi observado algum tipo de reabsorção.

Park et al. ${ }^{7}$ demonstraram uma intrusão de molares de 0.5 a $1.0 \mathrm{~mm}$ por mês, aplicando uma força em dentes posteriores de 200 a 300 gr., sem a presença de reabsorção notável da raiz ou problemas com a vitalidade desses dentes. Concluíram que com a simples colocação das mini-placas, o controle da direção e a quantidade de força, resultam no sucesso da intrusão do molar. 


\section{RELATO DO CASO}

Paciente do gênero feminino, com 39 anos de idade, leucoderma - na telerradiografia de perfil, através da avaliação cefalométrica de Steiner, apresentava: Classe I esquelética com tendência à Classe III, incisivos inferiores bem verticalizados e incisivos superiores bem posicionados na base apical. Na radiografia panorâmica observou-se: uma pneumatização do seio maxilar esquerdo em direção ao rebordo alveolar impossibilitando a reabilitação da ausência dentária do elemento 16 através de implante e uma atrofia severa do rebordo alveolar inferior esquerdo em direção ao canal mandibular, impossibilitando a implantação dentária dos elementos 36 e 37, ausentes no local. Ao exame clínico apresentava: ausência dos elementos dentários 16, 17, 36 e 37, sobremordida acentua$\mathrm{da}$, trespasse normal, cruzamento do elemento 18 , diastemas entre os elementos 33/34 e entre 22/23, desgaste nas bordas incisais exacerbado dos incisivos inferiores, rotação do dente 15 e extrusão de aproximadamente seis milímetros dos dentes 26, 27 e 28. A queixa principal da paciente era a presença de ruídos próximo aos ouvidos (estalos na Articulação Têmporo-Mandibular) e dores de cabeça ao final da tarde.

O tratamento inicial instituído foi a utilização de uma placa de relaxamento muscular com o intuito de se obter a relação cêntrica da paciente e melhora do quadro agudo de dor craniomandibular. Alguns meses após, foi instalado o aparelho fixo superior, utilizando uma barra transpalatina nos elementos dentários 15 e 25 para ancoragem com objetivo de intruir os molares superiores esquerdos e o dispositivo quadri-hélice para auxiliar no descruzamento do dente 18. Nesse momento, também foi feita a instalação do aparelho fixo inferior para obter a intrusão dos incisivos e nivelamento.

Após esta fase inicial estar concluída, o paciente foi submetido a uma antroplastia do seio maxilar esquerdo com a utilização de osso autógeno do mento. No mesmo procedimento, foi realizado um enxerto autógeno aposicional em bloco na região posterior do lado esquerdo da mandíbula. Ambos, para a recuperação vertical do osso alveolar perdido nessas áreas com o intuito de uma futura implantação dentária.

Como a intrusão ortodôntica com apenas ancoragem dentária não havia tido um resultado muito satisfatório até então, seis meses após a última cirurgia, foi instalada uma placa de titânio em forma de "L" na região apical dos elementos 26 e 27 com o objetivo de obter uma ancoragem ortodôntica rígida para a intrusão desses elementos. Também foram instalados três implantes (implant innovation-self tapping / USA), na região dos elementos dentários 16, 36 e 37.

Ocorreu a intrusão de seis milímetros nos dentes 26,27 e 28 em um período de cinco meses. Seis meses após, foram feitas as reaberturas dos implantes para a confecção das próteses provisórias, as quais foram instaladas um mês depois. Após cinco meses da colocação das próteses provisórias foi feita a remoção da placa. Durante a intrusão, arco retangular superior e inferior (.019" x .025") foram utilizados para melhorar o torque dos dentes 26 e 27 e intrusão dos incisivos inferiores, com intuito de aumentar o espaço protético para a recuperação do tamanho original dos mesmos.

Após a remoção do aparelho ortodôntico, foi feita a clareação dentária superior e inferior, instalação de prótese definitiva sobre os implantes e reabilitação estética dentária.

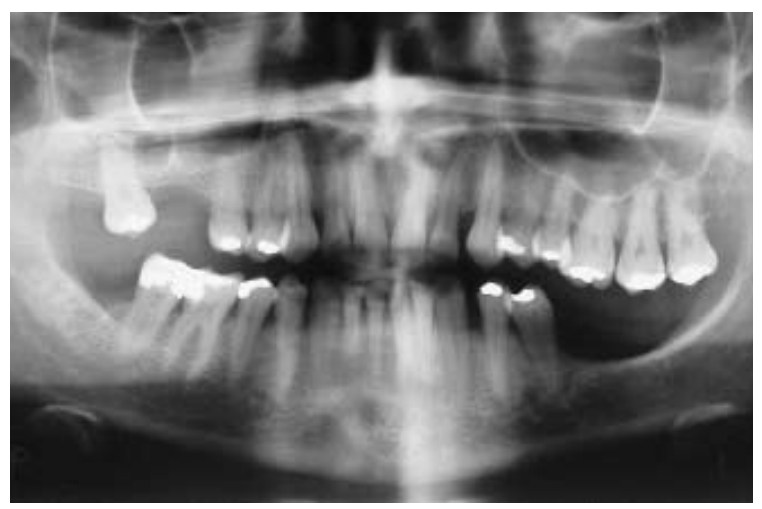

FIGURA 1 - Panorâmica de 18/11/98, evidenciando, dentre outros problemas, extrusão severa dos dentes 26, 27 e 28, atrofia do rebordo alveolar inferior esquerdo e pneumatização do seio maxilar ipsilateral. 


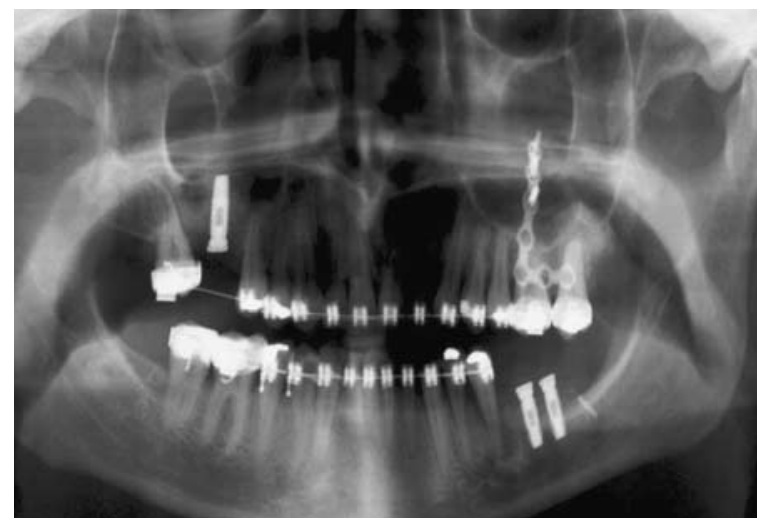

FIGURA 2 - Panorâmica de 18/08/02, demonstrando os implantes nas regiões dos 16, 36 e 37, uma mini-placa de fixação rígida na região infra-zigomática, com o intuito de ancoragem para a intrusão dos elementos 26 e 27 . Importante observar que a tentativa de intrusão desses dentes com apenas ancoragem dentária tinha tido pouca evolução até o momento.

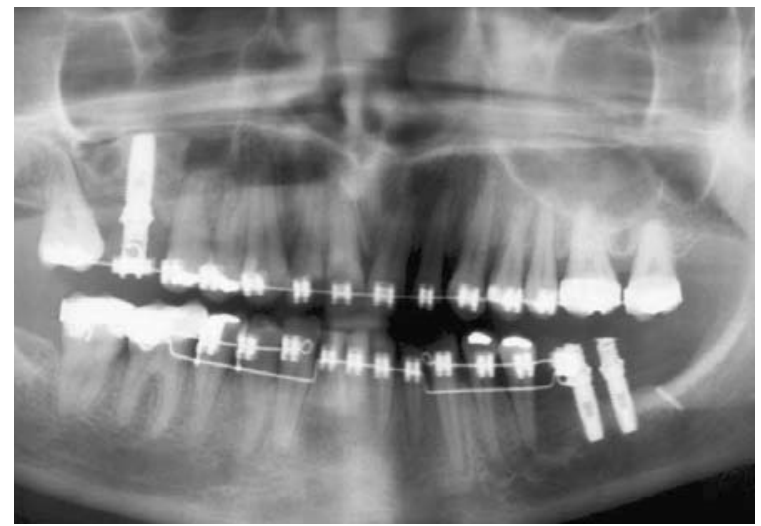

FIGURA 4 - Panorâmica 05/08/03, onde se observa a significativa intrusão dos dentes 26 e 27 .

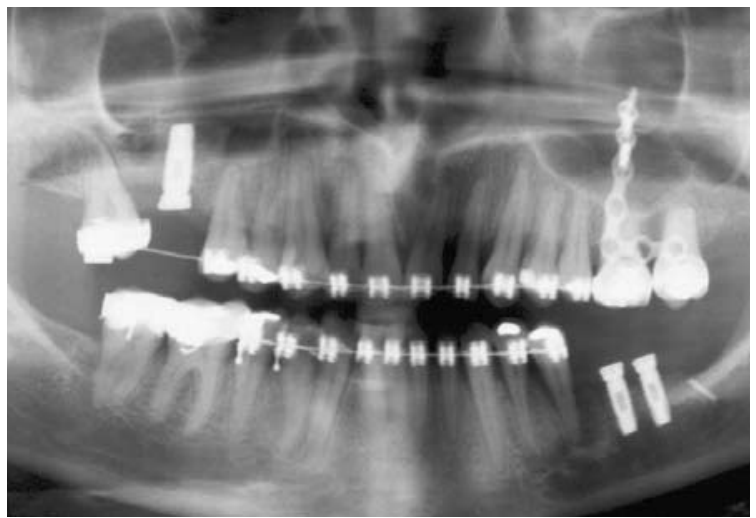

FIGURA 3 - Panorâmica intermediária 14/11/02, evidenciando 1 ano e 5 meses de tratamento ortodôntico e início da intrusão dos dentes 26 e 27 através da ancoragem rígida.

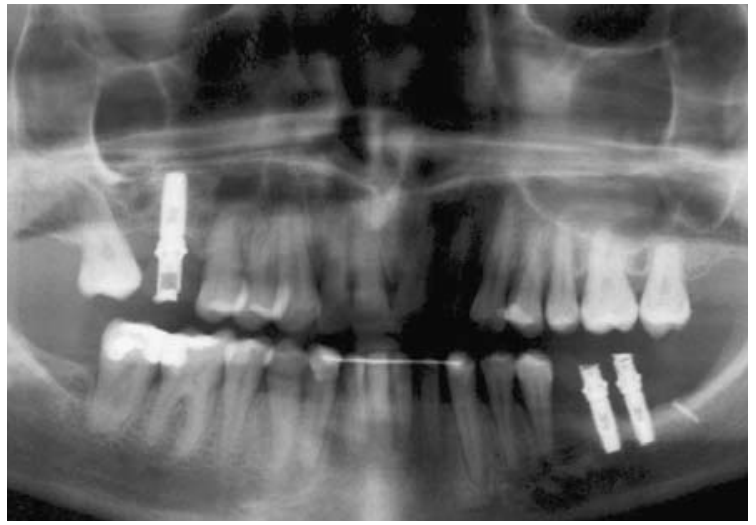

FIGURA 5 - Panorâmica final 29/04/04, após remoção do aparelho fixo.

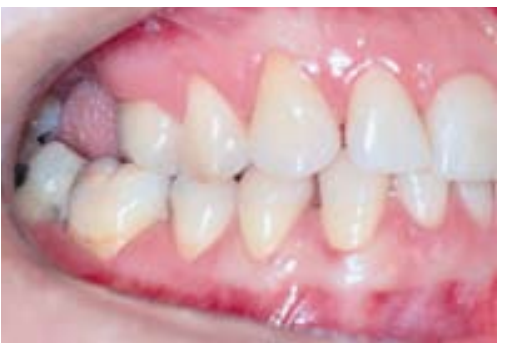

FIGURA 6 - Vista lateral direita intrabucal pré-tratamento.

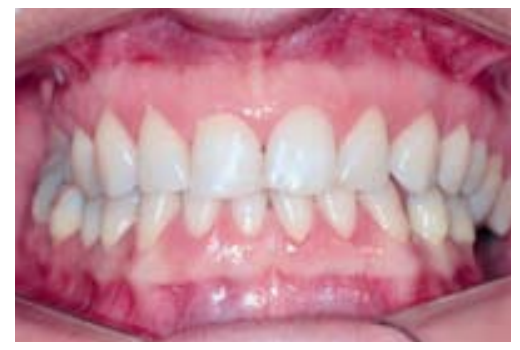

FIGURA 7 - Vista frontal intrabucal pré-tratamento.

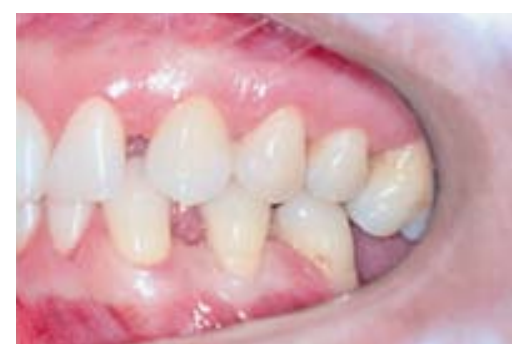

FIGURA 8 - Vista lateral esquerda intrabucal prétratamento. 


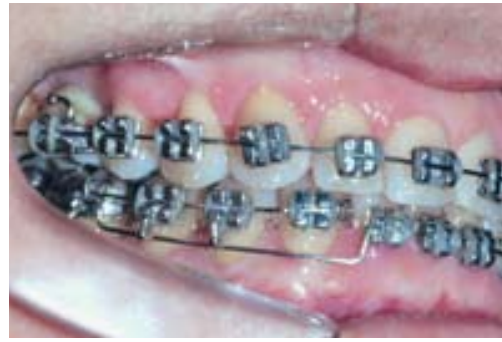

FIGURA 9 - Vista lateral direita intrabucal da fase de finalização do tratamento.

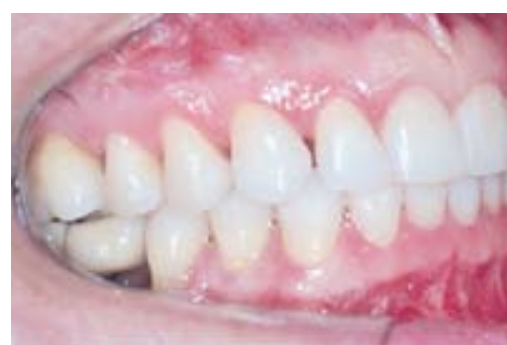

FIGURA 12 - Vista lateral esquerda intrabucal póstratamento.

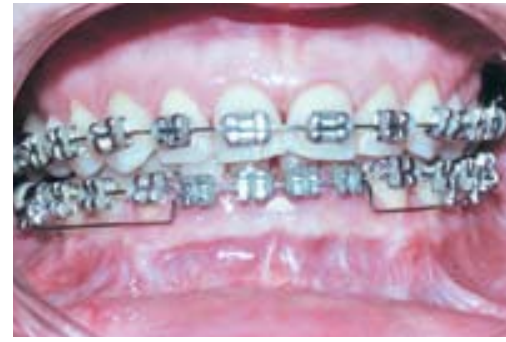

FIGURA 10 - Vista frontal intrabucal da fase de finalização do tratamento.

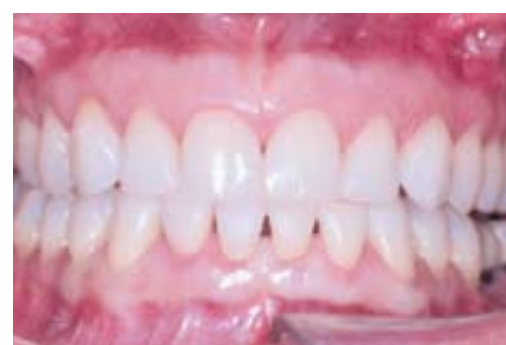

FIGURA 13 - Vista frontal intrabucal pós-tratamento.

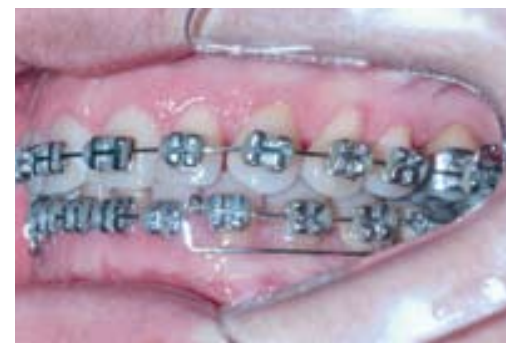

FIGURA 11 - Vista lateral esquerda intrabucal da fase de finalização do tratamento.

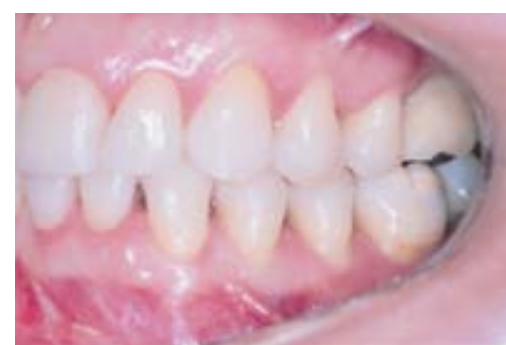

FIGURA 14 - Vista lateral direita intrabucal pós-tratamento.

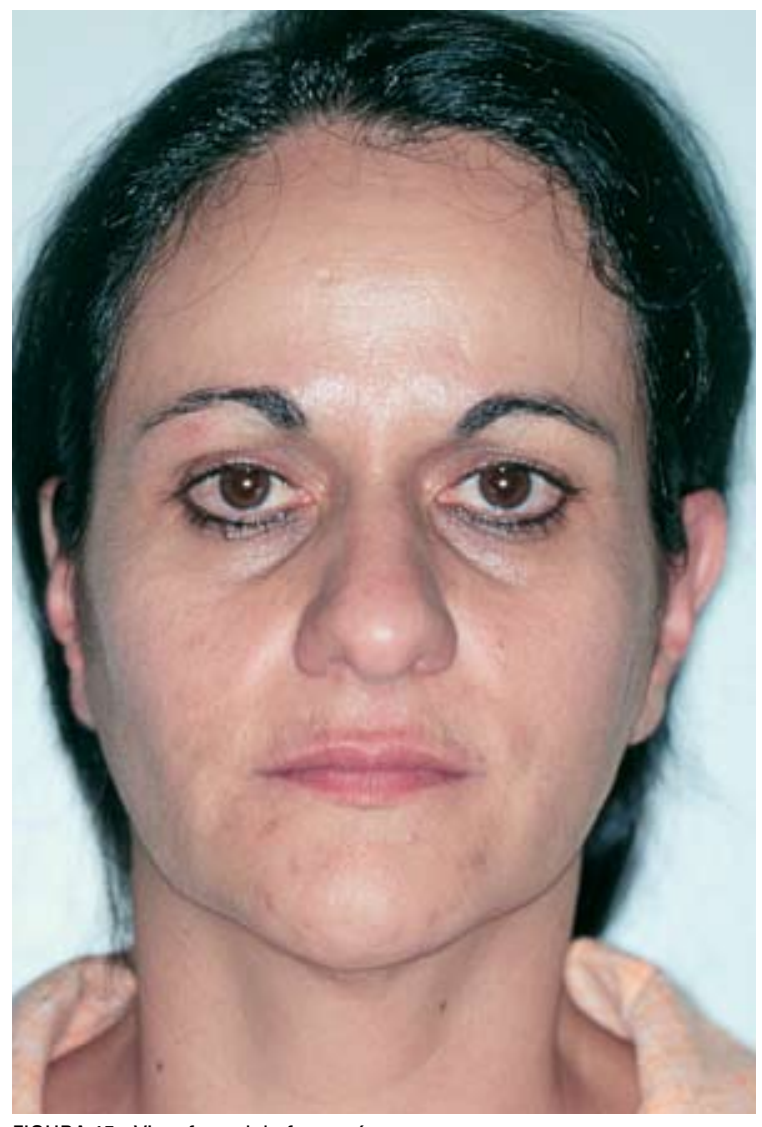

FIGURA 15 - Vista frontal da face pré-tratamento.

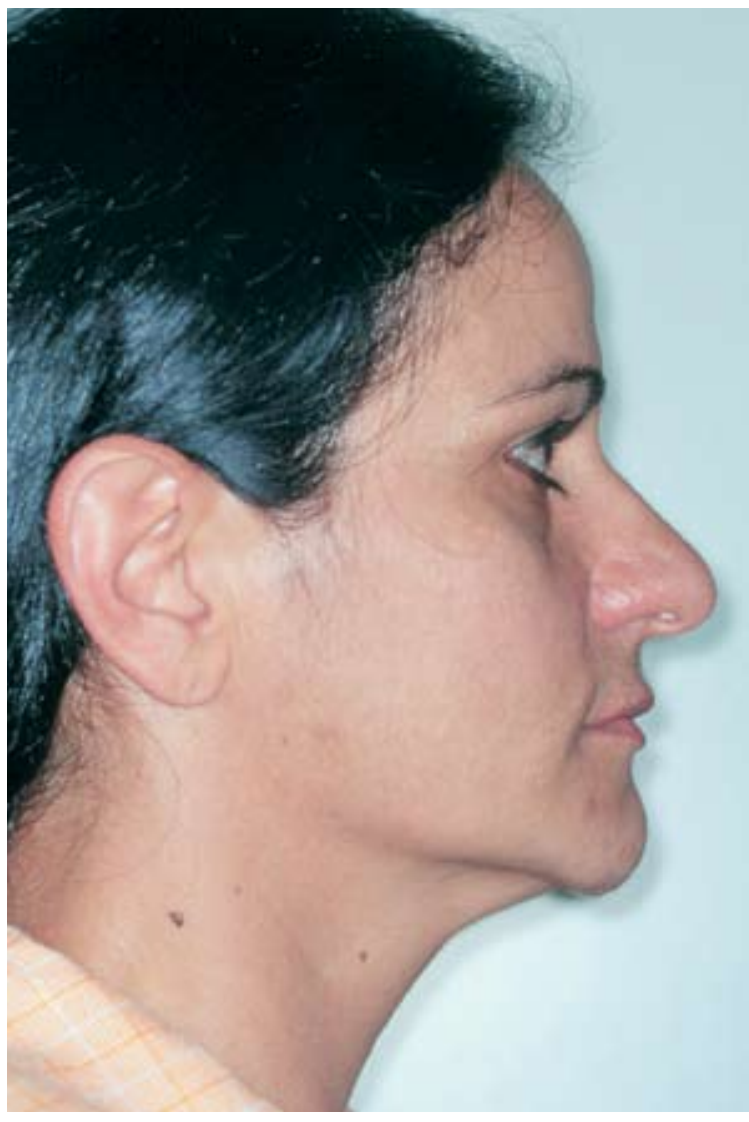

FIGURA 16 - Perfil pré-tratamento. 


\section{CONSIDERAÇÕES FINAIS}

Grande parte dos autores, $4,10,11$ acredita que a utilização da ancoragem rígida na Ortodontia proporciona a solução de casos que antes possuíam um prognóstico muito pobre. Principalmente casos em que exista algum tipo de dificuldade em obtê-la ou naqueles aonde somente com uma ancoragem dentária seria impossível de resolvê-los. A grande vantagem da utilização da ancoragem rígida é que podemos utilizar de cem até trezentos gramas ${ }^{3,4,10,11,12}$ como força para ancoragem, muito semelhante àquela que se utiliza nos aparelhos extrabucais, com vantagem de não haver o desconforto estético ao paciente e principalmente, não haver a dependência do paciente para o sucesso do tratamento ${ }^{1,5}$.

No presente estudo, utilizou-se a ancoragem ortodôntica rígida com sucesso para a intrusão de seis milímetros dos molares superiores no lado esquerdo, aonde o tratamento com ancoragem dentária não havia surtido efeito desejado. Sem esse tipo de ancoragem as soluções de tratamento seriam: o tratamento endodôntico dos dentes em questão, cirurgia periodontal para remoção de altura óssea associada à diminuição vertical das coroas, com coroa nos dentes envolvidos, mesmo assim, aquém do desejado devido à intensidade da extrusão; ou a outra opção seria reposição apical do bloco ósseo posterior da maxila, cirurgia de grande morbidade e bastante risco. As duas opções anteriores possuem um custo biológico e financeiro muito maior que a técnica empregada nesse caso, que sem sombra de dúvida foi a melhor opção de tratamento para esse tipo de problema.

Alguns autores discutem a melhor localização para a instalação do material de ancoragem, Park et al. ${ }^{7}$ afirmam que áreas com maior densidade e largura do osso cortical são consideradas as mais estáveis para as mini-placas e os mini-implantes. $\mathrm{Na}$ mandíbula, eles consideram as regiões retromolar e vestibular dos dentes posteriores como as mais indicadas. Já na maxila a área mais favorável é da sutura palatina mediana, devido à espessura do tecido e à densidade óssea. No presente estudo, a placa para ancoragem ortodôntica rígida foi instalada no pilar zigomático, pois possui uma estrutura óssea bem resistente e proporcionaria um vetor vertical para força intrusiva que seria utilizada.

Algumas complicações após a colocação das

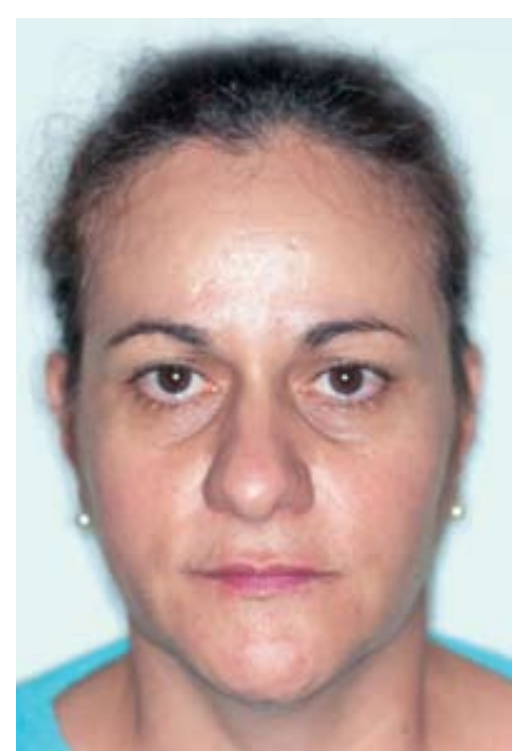

FIGURA 17 - Vista frontal da face pós-tratamento.

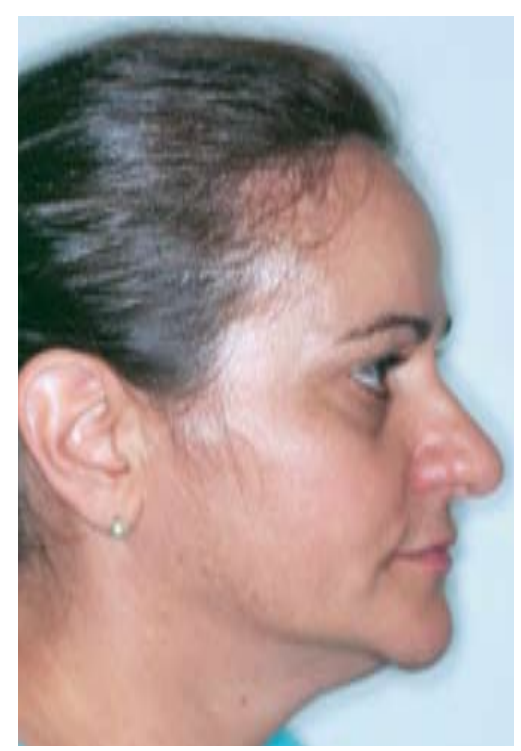

FIGURA 18 - Perfil pós-tratamento.

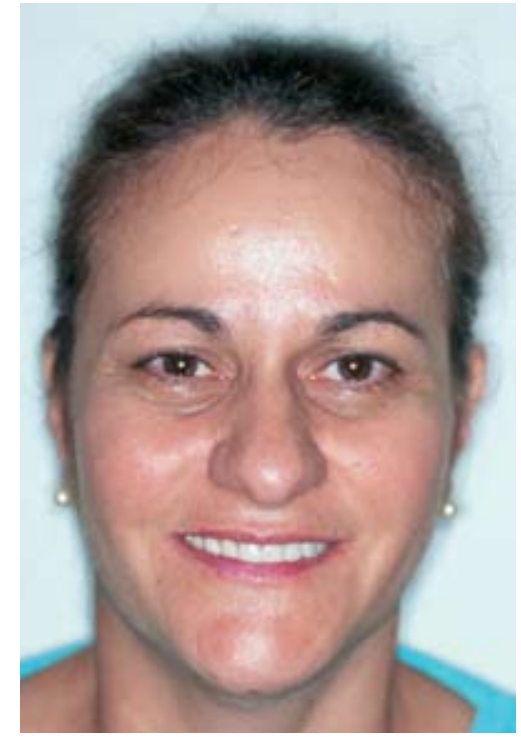

FIGURA 19 - Vista frontal da face sorrindo pós-tratamento. 
mini-placas ou parafusos de ancoragem podem ser observadas, tais como: inflamação no tecido em volta da região, hiperplasia gengival ao redor do pino de ancoragem, dificuldade da aplicação da força elástica quando a mini-placa ou pino estão muito próximos do dente a ser tracionado, causar danos às raízes ou aos nervos adjacentes e, finalmente, algum tipo de fratura ou afrouxamento ao dispositivo de tração $0^{5,7}$. Entretanto, alguns autores ${ }^{6}$ relataram em seus casos pouca inflamação tecidual durante o tratamento, nenhuma mobilidade do implante, não ocorreu infecção perioimplante, leve reabsorção radicular na região de furca e do ápice. Nesse trabalho, não foi observado nenhum tipo de problema em relação ao dispositivo de tração, entretanto, foi feito um controle rigoroso da higienização através da escovação mecânica e foi solicitado aplicar clorexidine a $0,12 \%$ de concentração topicamente com um cotonete.

Em relação ao dano causado no ápice ou na região de furca dos molares após o movimento intrusivo com a utilização da ancoragem rígida, alguns autores ${ }^{6,7}$ reportaram leve reabsorção radicular na região de furca e do ápice, entretanto, logo após, houve formação do cemento nas mesmas regiões. Inclusive, na microscopia fluorescente, foi verificado que ocorreu remodelação em volta da superfície radicular (cemento, periodonto e osso alveolar).

O presente estudo e grande parte da literatu$\mathrm{ra}^{2,3,11}$ concordam que o teor de recidiva é pequeno. Contudo, Sugawara et al..$^{10}$ relataram recidiva de aproximadamente 30\% da intrusão dos molares inferiores, também sugerindo uma sobrecorreção, se necessário.

Atualmente as mini-placas podem ser utilizadas na Ortodontia quando é necessária a ancoragem rígida, isto é, quando implantes, mini-placas, mini-implantes, parafusos de titânio ou pinos poderiam atuar como ancoragem para que movimentos dentários pudessem ser realizados em qualquer direção na ausência de forças recíprocas indesejáveis. Além disso, este tratamento possui algumas vantagens, tais como: eliminar a dependência da ancoragem intrabucal e extrabucal, estética favorável, redução da aparelhagem ortodôntica prevendo-se o resultado final ${ }^{12}$.

Através dos relatos anteriores e a experiência do caso relatado e outros ainda não concluídos, pode-se sugerir que a utilização da ancoragem rígida pode ser utilizada com bastante propriedade no tratamento ortodôntico aonde haja falta ou a necessidade de uma ancoragem máxima na Ortodontia.

\section{AGRADECIMENTOS}

Os autores agradecem ao ortodontista Carlos Saito e ao amigo e colega Leandro Neiva pela colaboração na execução deste trabalho.

Enviado em: Maio de 2004 Revisado e aceito: Junho de 2004 